\title{
Kulturhistoriska expeditioner på svensk landsbygd under 1920-talet
}

\author{
KARIN GustaVsSON*
}

Title: Investigations into Swedish peasant society in the 1920s.

Abstract: The aim of the project is to deepen the understanding of the investigations into Swedish peasant society that took place in the 1920s, in the shaping of ethnology as a scientific discipline. A specific source material consisting of photographs, drawings and descriptions of vernacular architecture, deriving from southern Sweden, will be used to contribute to research into the relationship between practice and scientific knowledge and to provide new perspectives on cultural heritage management knowledge in its scholarly context.

Key words: Peasant society, ethnology, vernacular architecture, fieldwork.

I min kommande avhandling med arbetsnamnet Kulturhistoriska expeditioner på svensk landsbygd under 1920-talet undersöker jag fältarbeten där byggnadsdokumentationer utfördes på landsbygden under 1900-talets första decennier. Nordiska museet och Sigurd Erixon, inledningsvis amanuens men från 1934 professor i folklivsforskning, hade nyckelroller men många andra aktörer var också verksamma. Samtidigt genomförde andra institutioner inventering och dokumentation av fler yttringar av en förmodat försvinnande allmogekultur dialekter, traditioner, seder och bruk, dräkt och heminredning - allt skulle samlas in, tecknas av, beskrivas, fotograferas samt sättas på museum och på så sätt räddas till framtiden. Samtiden benämnde fältarbetena som "expe- ditioner" - ett ord som andas koloniala erövringar och betvingande av territorier, något som då var högaktuellt genom olika upptäcktsresandes mer eller mindre hjältemodiga strapatser. Satsningen på dokumentation av allmogekulturen var brett förankrad i samhället och ansågs så viktig att en statlig utredning, den så kallade folkminneskommittén, tillsattes i 1920-talets början. Den skulle lämna förslag på hur ett systematiskt insamlingsarbete av framförallt folkminnen, traditioner och dialekter skulle organiseras så effektivt som möjligt. Ett nyckelord som ständigt återkommer i beskrivningarna av vad som skulle göras och hur det skulle ske är systematisk. Systematiken ansågs garantera en vetenskaplig nivå i arbetet. Avhandlingen sätter expeditionernas praktik i 
104 fokus och behandlar förhållandet mellan praktiskt arbete och vetenskaplig kunskap. De fältarbetare som utförde undersökningarna var utsända sommartid i grupper om två till fyra personer. De var inte alltid skolade vetenskapsmän utan arkitekter under utbildning eller studenter i konsthistoria, folklivsforskning eller andra ämnen, samtliga män. Under expeditionerna utsattes deltagarna för umbäranden i form av ansträngande cykelfärder med tung packning och inkvartering i enkelt logi. Fältarbetarna hade inte alltid själva vetenskapliga ambitioner, men de arbetade med systematiken som vetenskaplig metod, och de var utsända i ett vetenskapligt syfte. Uppdragsgivarna använde sedan det material som åstadkoms under fältarbetsperioderna i form av ritningar, beskrivningar och foton som källor till ett vetenskapligt beskrivande av landsbygdens byggnadskultur.

Avhandlingen tar sin teoretiska utgångspunkt i den tyske vetenskapsmannen Ludwik Flecks teori om tankestil, det stabila tankekollektivet och uppkomsten av ett vetenskapligt faktum, som publicerades första gången 1935 och översattes till svenska $1997 .{ }^{1}$ Fleck, som var naturvetare (medicinare), undersökte hur vetenskaplig kunskap uppstår, vilket är en central fråga i min studie av de kulturhistoriska expeditionerna. Enligt Flecks modell uppstår vad han benämner som tankekollektiv när minst två individer möts och utbyter tankar. I tankekollektivet utbildas en särskild tankestil. Fleck skiljer på momentant och stabilt tankekollektiv, där det förstnämnda är flyktigt och snabbt förgängligt men ändå kittar ihop individerna. Det stabila tankekollektivet uppstår när någon form av organiserad grupp möts. Om gruppen existerar tillräckligt länge blir tankestilen fixerad och formaliserad till sin struktur, och den formella strukturen hotar att ta över den kreativitet som ursprungligen präglade tankekollektivet. Då inträder det stadium som Fleck kallar tanketvång då allt mer har blivit underförstått och färdigdefinierat (Fleck 1997:103). Den krets av folklivsforskare, konstvetare och arkitekter som arbetade med kulturhistoriska dokumentationer kan rubriceras som ett stabilt tankekollektiv enligt Flecks modell. De uppfattningar om verkligheten som de formulerade kan beskrivas som deras tankestil.

Det faktum att Fleck var naturvetare är inte något hinder för att använda hans teser i en kulturhistorisk kontext. Hans teorier användes till exempel av etnologen Eva Fägerborg i hennes avhandling 1996. ${ }^{2}$ Under 2000-talets första decennium skrevs flera idéhistoriska avhandlingar, som bygger på kulturhistoriskt källmaterial med Fleck som teoretiker.

I avhandlingsarbetet använder jag till största del material från södra Sverige. Såväl byggnadsbeskrivningar och ritningar som foton är viktiga källor. Ur fotografierna går att utläsa ytterligare information om fältarbetspraktiken, som inte finns uttryckt i text. Den fotografiska tekniken kan också ses som ett redskap i vetenskapliggörandet av landsbygden, en teknik som skapade exakta och till synes objektiva bidrag till forskningen. Men vad som fastnade på bild var resultatet av en selektion, en blick, som sökte det som ansågs autentiskt och ursprungligt. Studiet av expeditionernas fotografier innebär också en uppmärksamhet på det som inte syns på bild, det som valdes bort. Medan kameran bara kunde registrera det som faktiskt syntes, kunde på ritningar däremot göras rekonstruktioner av äldre förhållanden. I de texter som ledsagar ritningar och foton ges ibland mycket detaljerade beskrivningar av specifika byggnadskonstruktioner, och förhållanden i äldre tider skild- 


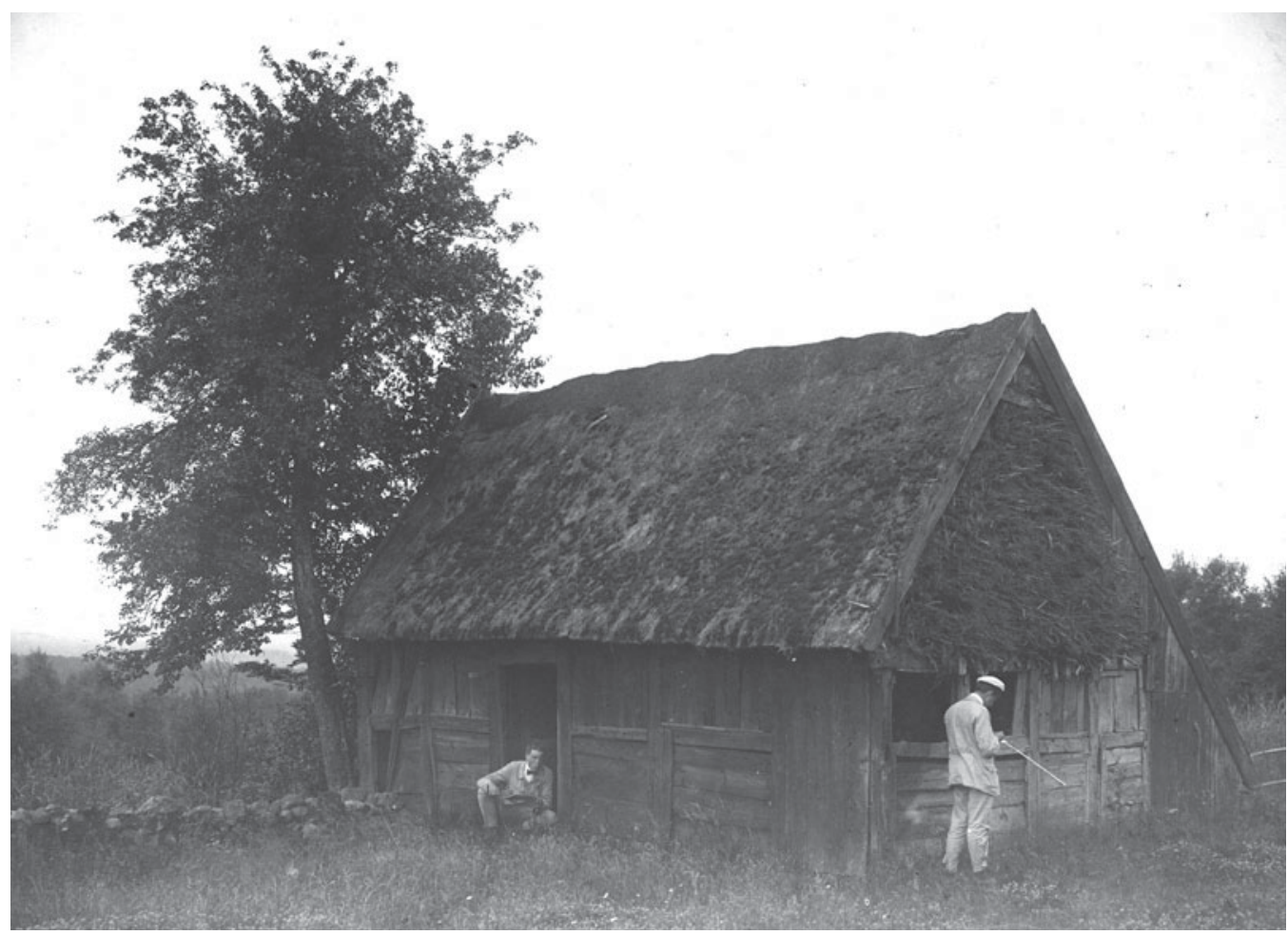

Två fältarbetare under dokumentation av en ekonomibyggnad på Hallandsåsen, i Boarp, Hjärnarps socken, Skåne 1921. Fotograf okänd, original $i$ Helsingborgs museers arkiv.

ras i syfte att ge en uppfattning om en byggnads eller gårds utformning i förgången tid.

Avhandlingens källor finns främst i olika offentliga arkiv och består av det dokumentationsmaterial som blev resultatet av expeditionernas arbete, korrespondens mellan olika aktörer samt olika typer av offentligt tryck, som exempelvis riksdagsmotioner.

Avhandlingen kommer också behandla kulturarvsprocesser, kulturarvsförvaltning och minnespolitik. Målet med expeditionerna var främst inomvetenskapligt. Genom ett systematiskt fältarbetande skulle skapas underlag för forskning om allmogekulturen. Att förmå landsbygdsbefolkningen att vidmakthålla sina äldre byggnader så att de kunde finnas kvar in $i$ framtiden ingick inte $i$ uppdraget. Men många av de objekt som expeditionerna uppmärksammade kom att finnas kvar, och fick senare status av officiellt kulturarv. Dagens kulturarvsförvaltning arbetar med värderingsinstrument och urvalsprinciper som är förbluffande lika dem som expeditionerna hade vid sin selektion av objekt för dokumentation, trots att bevarande av kulturvärden då inte stod på agendan. Det går att nå fördjupad kunskap om dagens kulturarvssektors värderingsgrunder genom att studera expeditioner- 
106 nas väljande och bortväljande och den betydelse det fick för kulturarvsprocesser och minnespolitik. Avhandlingen syftar därmed till att bli ett bidrag till diskussionen om aktuell minnespolitik och kulturarvsförvaltningens ideologiska hemvist.

I avhandlingen kommer vissa internationella jämförelser att göras. Det arbete som bedrevs i Sverige med att dokumentera allmogekulturen var ingen isolerad företeelse utan hade både förebilder och efterföljare $\mathrm{i}$ andra länder. Nyckelpersoner i verksamheterna stod i tät kontakt med varandra för utbyte av både praktiska erfarenheter och ideologiska ställningstaganden, över nationsgränserna.

Avhandlingsarbetet bedrivs sedan våren 2009 vid Etnologiska avdelningen, Institutionen för kulturvetenskaper vid Lunds universitet. Det första året finansierades av Gyllenstiernska Krapperupsstiftelsen.

\section{NOTER}

1. Ludwik Fleck: Uppkomsten och utvecklingen av ett vetenskapligt faktum. Inledning till läran om tankestil och tankekollektiv. Eslöv: B. Östlings bokförl. Symposion 1997.

2. Eva Fägerborg: Miljoner och my. Kunskapssyn och tänkande på en verkstadsindustri. Stockholm: Nordiska museet 1996.
*Karin Gustavsson, doktorand

Adress: Institutionen för kulturvetenskaper, Box 117, SE-221 00 Lund, Sverige

E-mail: karin.gustavsson@kultur.lu.se

Web: http://www.kultur.lu.selo.o.i.s?id= 20834 opp = KarinGustavsson 